\title{
History of childhood abuse in Portuguese parents ${ }^{\text {th }}$
}

\author{
Bárbara Figueiredo $^{\mathrm{a}, *}$, Antonia Bifulco ${ }^{\mathrm{b}}$, Carla Paiva ${ }^{\mathrm{a}}$, Ângela Maia ${ }^{\mathrm{a}}$, \\ Eugénia Fernandes ${ }^{\text {a }}$, Raquel Matos ${ }^{\text {a }}$ \\ a Department of Psychology, University of Minho, Braga, Portugal \\ b Lifespan Research Group, Royal Holloway, University of London, London, UK
}

Received 14 May 2002; received in revised form 4 November 2003; accepted 30 November 2003

\begin{abstract}
Objective: The study examines the self-reported prevalence of childhood physical and sexual abuse in a large sample of Portuguese parents.

Method: Nearly 1,000 parents (506 mothers and 426 fathers) were selected through public primary schools from the Northern area of Portugal. All completed the Portuguese version of the Childhood History Questionnaire (CHQ) [Journal of Family Violence 5 (1990) 15].

Results: Results show that the prevalence of abuse was $73 \%$, but more severe physical abuse involving sequelae/injury was reported by $9.5 \%$. Most physical abuses began prior to age 13 , with half continuing after age 13 . No gender differences were found for rates of physical abuse. However, among the milder physical abuse without sequelae/injury, those women who experienced "whipping" or "slapping/kicking" were more likely to do so from their mothers than fathers. Among men who were "slapped/kicked" this was more likely to be from their fathers. Low rates of sexual abuse were found at $2.6 \%$ with no gender or age differences. Lack of a supportive adult in childhood related to the more severe abuses, but only in adolescence. Portuguese rates of abuse were consistently lower than those reported in USA and Spanish studies using the CHQ.

Conclusions: This is the first retrospective, self-report study of childhood abuse in a large sample of Portuguese parents and, even with a participation rate of $69 \%$, shows lower rates than in US and Spanish samples.

(C) 2004 Elsevier Ltd. All rights reserved.

Keywords: Childhood physical abuse; Childhood sexual abuse; CHQ; Portugal

\footnotetext{
is This study is part of a longitudinal research study, supported by a national grant (POCTI/PSI/14276/1998, Professor Doutora Barbara Figueiredo, PI).

* Corresponding author address: Departamento de Psicologia, Universidade do Minho, Campus de Gualtar, 4700 Braga, Portugal.
} 


\section{Introduction}

Estimating the prevalence of child and adolescent maltreatment has been the aim of many research investigations in recent years. The importance of such study is attested to by the negative long term effects of abuse, both in terms of high rates of adult psychiatric disorder (Dube et al., 2001; Egami, Fond, Greenfield, \& Crum, 1996; Kessler, Davis, \& Kendler, 1997; MacMillan et al., 2001; Peters \& Range, 1995; Rosen \& Martin, 1996), poor adult functioning (Belt \& Abidin, 1996; Brayden, Deitrich-MacLean, Deitrich, Sherrod, \& Altemeier, 1995; Crouch, Milner, \& Caliso, 1995; Figueiredo, Fernandes, Matos, \& Maia, 2001; Kinzl, Traweger, \& Bielb, 1995) pregnancy risk and parenting issues (Benedict, Paine, Paine, Brandt, \& Stallings, 1999; Grimstad \& Schei, 1999; Milner, Robertson, \& Rogers, 1990). Two approaches have typically been taken to studying abuse: some studies have estimated rates through those officially registered and others by historical reports from individuals in the community. The problem with the former is the large number of unregistered abuses. Whilst the latter approach typically reports higher prevalence rates, problems revolve around issues of obtaining accurate retrospective assessments and the definitions used by the researchers (Epps, Carlin, \& Ward, 1999; Epstein \& Bottoms, 1998; Fish \& Scott, 1999; Finkelhor, 1984).

The retrospectively reported prevalence of serious physical abuse in childhood and adolescence, utilizing self-report measures covers a broad range from $14 \%$ to $50 \%$ in community samples (Browne \& Hamilton, 1998; Dube et al., 2001; Egami et al., 1996; MacMillan et al., 2001; Nobes, Smith, Upton, \& Heverin, 1999). Variation has been attributed as much to methodological issues such as the instruments used and the definition of abuse employed, as to characteristics of the community studied (e.g., Finkelhor, 1984; Gelles \& Loseke, 1993; Polusny \& Foulette, 1995).

Similar measurement issues hold for sexual abuse during childhood and adolescence. Overall prevalence estimates are lower, ranging between 5-10\% and 35-40\% in different samples using similar measures (Benedict et al., 1999; Brayden et al., 1995; Dube et al., 2001; Epstein \& Bottoms, 1998; Fish \& Scott, 1999; Grimstad \& Schei, 1999; Kinzl et al., 1995; Liem \& Boudewyn, 1999; Lynksey \& Fergusson, 1997; MacMillan et al., 2001; Melchert, 2000; Peters \& Range, 1995; Polusny \& Foulette, 1995; Shapiro \& Levendosky, 1999). A large review of almost 30 empirical studies in 20 different countries found rates ranging from $7 \%$ to $36 \%$ for women and $3 \%$ to $29 \%$ for men (Finkelhor, 1994). The severity and frequency of abuse also varies in different studies, and investigators have pointed out that in the higher range more than half of the reports of sexual abuse referred to single incidents (Benedict et al., 1999; Epstein \& Bottoms, 1998), although sexual abuse is highly likely to be repeated and such abuse is usually more damaging (Kinzl et al., 1995).

The presence of both physical and sexual abuse in childhood is also common (e.g., Dube et al., 2001; Fish \& Scott, 1999; Liem \& Boudewyn, 1999; Rosen \& Martin, 1996), and the assessment of both when considering prevalence rates is advocated in terms of giving a broader picture of assessing childhood experiences and the multiple factors that determine adult disorder (Bifulco, Brown, \& Harris, 1994; Kessler et al., 1997). There are clear benefits to utilizing measures, which assess both experiences, such as the Childhood History Questionnaire (CHQ) (Milner et al., 1990). This measure has a low threshold for identifying abuse: two US studies utilizing the CHQ measure of physical and sexual abuse show rates over 90\% (Milner et al., 1990; Litty, Kowalski, \& Minor, 1996). However, rates are considerably lower for more severe abuses, such as physical abuse with sequelae/injury (20.9\%) and lowest for sexual abuse $(10 \%)$. 


\section{Characteristics of abuse}

Age. Most community-based studies show the onset of physical abuse to be more common before the onset of adolescence (e.g., Crouch et al., 1995; de Paúl, Milner, \& Múgica, 1995; Milner et al., 1990), but sexual abuse typically occurs later (e.g., Benedict et al., 1999; Epstein \& Bottoms, 1998; Lynksey \& Fergusson, 1997). This result also holds for officially registered abuses (Egami et al., 1996; McGuigan \& Pratt, 2001; Mollerstrom, Patchner, \& Milner, 1995; US Department of Health and Human Services, 1986, 1988, 1996).

Gender. The relationship of type of abuse to the gender of victims is somewhat disputed. Whereas many studies have found no gender difference in victims of physical abuse (e.g., Browne \& Hamilton, 1998; de Paúl et al., 1995; Dube et al., 2001; Fish \& Scott, 1999; Liem \& Boudewyn, 1999; Milner et al., 1990), some have shown the more severe physical abuses involving injury more often reported by men (e.g., Belt \& Abidin, 1996; Rosen \& Martin, 1996). The majority of studies have shown sexual abuse to be more common in women (e.g., Belt \& Abidin, 1996; Browne \& Hamilton, 1998; de Paúl et al., 1995; Dube et al., 2001; Epstein \& Bottoms, 1998; Fish \& Scott, 1999; Liem \& Boudewyn, 1999; Milner et al., 1990; Peters \& Range, 1995; Rosen \& Martin, 1996); and "mostly show rates for females to be 1.5-3 times that of males" (Finkelhor, 1994, p. 41). Occasionally, however, reports have found no gender difference (e.g., Melchert, 2000). While officially registered abuses show no significant differences by gender and age for physical abuse (Egami et al., 1996; McGuigan \& Pratt, 2001; Mollerstrom et al., 1995; US Department of Health and Human Services, 1986, 1988, 1996), they show a preponderance of female victims of sexual abuse (e.g., Mollerstrom et al., 1995).

Perpetrator. Physical abuse tends to be equally perpetrated by mothers or fathers (e.g., Browne \& Hamilton, 1998; Nobes et al., 1999), and to be largely confined to family members. Sexual abuse is more often perpetrated by males, more often outside the family, a large proportion of whom are unrelated to the victim (Benedict et al., 1999; Kinzl et al., 1995). However, when extended family is taken into account rates of familial sexual abuse have been shown to be equal to those outside the family (e.g., Brayden et al., 1995). When officially registered sexual abuses are examined these are much more frequently perpetrated by fathers than mothers (e.g., Mollerstrom et al., 1995).

Culture. Most studies of childhood abuse have been undertaken in English speaking countries notably the United States (e.g., Crouch et al., 1995; Litty et al., 1996; Milner et al., 1990), the United Kingdom (e.g., Browne \& Hamilton, 1998; Nobes et al., 1999), Canada (e.g., MacMillan et al., 2001), and New Zealand (e.g., Lynksey \& Fergusson, 1997; Mullen, Martin, Anderson, Romans, \& Herbison, 1993). There is generally much less known about the prevalence of abuse in wider Europe, particularly utilizing the same measures (Finkelhor, 1994). However, one study in the Basque part of North Spain (de Paúl et al., 1995) among university students compares rates with those reported in the US using the CHQ (Milner et al., 1990). This study produced the same high overall rate for any level of abuse (93.8\%, compared with the US 91.7\%); but a somewhat lower rate in Spain, for severe physical abuse with sequelae/injury (15.2\% vs. $20.5 \%$ ). Both studies showed that physical abuse with and without sequelae/injury tends to occur usually before age 13 , but to continue after age 13 , with few in the adolescent period alone. Rates of sexual abuse were also similar at $12.2 \%$ for the Spanish study and $10 \%$ for the US. However, a higher rate of sexual abuse in males was found in the Spanish series $(9.7 \%$ vs. $4.3 \%)$. 
The present study was designed to: (1) establish the self-reported prevalence of physical and sexual abuse in a sample of parents in Portugal and compare this with rates in the USA and Spain; (2) examine the prevalence of abuse by gender and age in terms of pre-or post adolescent first occurrence; (3) examine the gender of perpetrators of physical abuse in relation to gender of victim; (4) examine care in childhood in terms of adult support and predictability of routine in childhood as negatively related to abuse.

Given differences in family organization, rural versus urban living, religious affiliation and socioeconomic status in different areas of Europe, the widespread investigation of rates of childhood and adolescent abuse is required to understand both the different contexts of such abuse and its lasting ill-effects in different cultures and community settings. This will serve to inform not only the scientific understanding of the effects of such abuse in different contexts, but will also inform the countries concerned about the extent of the abuse problem in their own communities. To date there has been no systematic investigation of rates of childhood and adolescent abuse in Portugal. The present study aims to establish such rates in a large sample of community-based parents by use of the standardized CHQ self-report measure.

\section{Methods}

\section{Participants}

Sample selection. The study participants were parents of children randomly selected in five public elementary schools in different residential areas (rural/urban) of Northern Portugal (Porto, Maia, Braga, and Chaves). All the parents whose children attended the selected schools were contacted. Initial pilot work was undertaken with parents of children in the second year of elementary school. This evaluated the feasibility of procedures and subject's compliance. The first translation of the CHQ in Portuguese was prepared and piloted (Matos, Figueiredo, Maia, Fernandes, \& Ribeiro, 1999).

Formal contact was made with the five schools for permission to conduct the research, and formal ethical permission granted from the educational authorities (DREN, Direcção Regional da Educação do Norte). The parents were first invited to a meeting with the teachers to explain the aims of the study, confidentiality issues and the importance of participation. The teachers gave the questionnaires and letters of consent in sealed envelopes to the children who handed them to their parents. The subjects who were willing to participate completed the questionnaires at home (mothers and fathers separately) and then returned them to the teachers in the sealed envelope. Whenever the subjects had questions or problems in completing the questionnaires, the researchers met with them to clarify issues.

The questionnaires were sent to every parent or surrogate parent $(N=1480)$ having at least one child attending the selected schools. The overall rate of compliance from parents (i.e., in returning the questionnaires) was $69 \%(N=1021)$, and the rate of correctly completed and returned questionnaires was $63 \%$ [68\% (506) of the mothers and 58\% (426) of the fathers].

Participant's social-demographic data. The average age of the series was 35.8 years old for the mothers (with a wide range from 22 to 77 years old - the latter reflecting a grandmother looking after the child) and 38.6 years old for the fathers (with a wide range from 25 to 84 years old, again the latter representing a grandfather). 
The sample appears to be representative of Portuguese parents in terms of demographic characteristics, when compared with Portuguese National Statistics (Instituto Nacional de Estatística, 1999). For example, almost all the participants had Portuguese nationality (93\% of the fathers and $90.2 \%$ of the mothers), with $6.4 \%$ of the mothers and $5.5 \%$ of the fathers born in other Portuguese speaking countries (Angola, Mozambique, Cabo Verde, and Brazil). The majority of the subjects were practicing Roman Catholics (84.9\% of the mothers and $69.5 \%$ of the fathers). Only a small proportion belonged to other Christian denominations or other religions (2.3\% of the mothers and $1.7 \%$ of the fathers). However, a substantial proportion had no religious affiliation: $12.8 \%$ of the mothers and $28.8 \%$ of the fathers. Almost all subjects $(95.7 \%)$ originated from three of the cities studied in North Portugal: Porto, Maia, and Braga.

In terms of education, around a third of parents failed to complete compulsory schooling, and more than a sixth had a degree or higher in further education. The most common occupations were lower middle class; thus a third of the sample were in "non-specialized technical" occupations (such as technical assistants, master workman, foreman, etc.). Most of the parents were employed, as many as $93.8 \%$ of the fathers and $77.4 \%$ of mothers were in paid work. This is representative of rates in Northern Portugal (Instituto Nacional de Estatística, 1999), with one of the highest rates of female employment in Europe (European Commission, 2002). There was a wide range of family income, but with only $8 \%$ of the mothers and $3.4 \%$ of the fathers earning less than the minimum national salary.

Almost all the sample ( $89 \%$ of the mothers and $96.9 \%$ of the fathers) was married or cohabiting. Although the family size ranged from 1 to 6 children, half of the parents had 2 children $(51.9 \%$ and $50.9 \%$, respectively). Nearly all had less than 4 (97.6\% for mothers and $98.1 \%$ for fathers). Only very few had stepchildren (.4\% mother and $1 \%$ fathers). Most couples were living in a nuclear family $(90.8 \%)$, with only $9.2 \%$ of the couples living with other family members besides the children. Family structure was similar to that in Northern Portugal as a whole (Instituto Nacional de Estatística, 1999).

\section{Measures}

The study used a two-stage design: first, a large-scale questionnaire assessment of parents' experiences in childhood and second, an intensive interview assessment of a selected sub-sample. Only the first stage is described in this report. Parents were given additional questionnaires but only the CHQ is described in this report.

Childhood History Questionnaire (CHQ) (Milner et al., 1990). CHQ is a retrospective, self-report assessment of physical and sexual abuse and care during childhood and adolescence. It includes 14 questions about the presence and frequency (never, rarely, occasionally, often, or very often) of different kinds of physical and sexual abuse. These are repeated in four sections identifying the experience of abuse either before and/or after age 13, and the witnessing of abuse in either age group totalling 56 questions. The main CHQ question is: "As a child, did you receive any the following from one of your parents or another adult before you were 13?" For each item the respondent is asked to identify the perpetrator where relevant.

Physical abuse is defined in terms of behaviors including "whipping, slapping/kicking, poking/ punching, or hair pulling," and each is classified according to whether this resulted in an injury or sequelae/injury such as "bruises/welts, cuts/scratches, dislocations, burns or bone fractures."

Sexual abuse involves four kinds of abusive behaviors including: "inappropriate touching, sexual fondling, intercourse/rape, and exhibitionism/flashing." 
Care in childhood. The CHQ also includes three items concerning care in childhood. It asks for the frequency with which there was "an adult who really cared about" the person and another asking about security or predictability of childhood routine in terms of the frequency with which "life was predictable." Negative response to these will be included in the analysis as markers for lack of care as correlates of abuse.

The CHQ internal consistency for the present sample was alpha $=.88$ for the 56 abuse items, and .83 for the overall 59 items of the questionnaire.

\section{Data analysis}

Statistical analysis was undertaken with SPSS-10. Within group comparisons were made using chisquare tests with Yates' correction, as well as between-group comparisons utilizing published figures from US and Spanish comparative studies.

\section{Results}

\section{Prevalence of abuse}

Prevalence rates of any reported abusive experience were examined by type of abuse and gender (Table 1). Although abuse was very common, reported by $73.2 \%$ of the sample, this was mainly accounted for by low levels of physical abuse, including slapping, without resulting injury. Serious physical abuse with sequelae/injury occurred for $9.5 \%$ of the sample. Sexual abuse was present for $2.6 \%$ of the series. Chi-square tests were used to compare overall reported abuse in females and males. No significant differences were found for rates of abuse for males and females in any category; for example, any kind of abuse reported by $71.7 \%$ of the women and $74.9 \%$ of the men, physical abuse without sequelae/injury reported by $70.1 \%$ of the women and $74.3 \%$ of the men, physical abuse with sequelae/injury reported by $10.2 \%$ of the women and $8.6 \%$ of the men, and sexual abuse reported by $2.7 \%$ of the women and $2.6 \%$ of the men.

\section{Physical abuse-age and gender}

Age at first experience of abuse was examined for physical abuse, both with and without sequelae/injury. Abuse in either category nearly always began before age 13 , but also very commonly continued after age 13.

Table 1

Prevalence of abuse and gender

\begin{tabular}{lllll}
\hline $\begin{array}{l}\text { Gender of } \\
\text { respondent }\end{array}$ & $\begin{array}{l}\text { Any kind of abuse } \\
(N=806)^{\mathrm{a}}, \%(N)\end{array}$ & $\begin{array}{l}\text { Physical abuse without } \\
\text { sequelae/injury }(N=823), \%(N)\end{array}$ & $\begin{array}{l}\text { Physical abuse with } \\
\text { sequelae/injury }(N=831) \%(N)\end{array}$ & $\begin{array}{l}\text { Sexual abuse } \\
(N=835) \%(N)\end{array}$ \\
\hline Female & $71.7(312)$ & $70.1(309)$ & $10.2(46)$ & $2.7(12)$ \\
Male & $74.9(278)$ & $74.3(284)$ & $8.6(33)$ & $2.6(10)$ \\
Total & $73.2(590)$ & $72.1(593)$ & $9.5(79)$ & $2.6(22)$ \\
$p$ & $n s$ & $n s$ & $n s$ & $n s$
\end{tabular}

${ }^{a}$ Missing values: 932 parents answered the questionnaire, but not all completed all the CHQ items. 
Table 2

Age at physical abuse, severity and gender

\begin{tabular}{|c|c|c|c|c|c|}
\hline $\begin{array}{l}\text { Gender of } \\
\text { respondent }\end{array}$ & No abuse, $\%(N)$ & $\begin{array}{l}\text { Before } 13 \text { only, } \\
\%(N)\end{array}$ & $\begin{array}{l}\text { After } 13 \text { only, } \\
\%(N)\end{array}$ & $\begin{array}{l}\text { Before and } \\
\text { after } 13, \%(N)\end{array}$ & Total, $\%(N)$ \\
\hline \multicolumn{6}{|c|}{ A. Physical abuse without sequelae/injury } \\
\hline Female & $29.9(132)$ & $25.9(114)$ & $1.8(8)$ & 42.4 (187) & $100(441)$ \\
\hline Male & $25.6(98)$ & $23.8(91)$ & $2.6(10)$ & $47.9(183)$ & $100(382)$ \\
\hline Total & $27.9(230)$ & $24.9(205)$ & $2.2(18)$ & $45.0(370)$ & $100(823)$ \\
\hline$p$ & $<.000$ & $<.000$ & $<.000$ & $<.000$ & $<.000$ \\
\hline \multicolumn{6}{|c|}{ B. Physical abuse with sequelae/injury } \\
\hline Female & $89.7(403)$ & $1.8(8)$ & $1.1(5)$ & $7.4(33)$ & $100(449)$ \\
\hline Male & $91.3(349)$ & $3.7(14)$ & $0.8(3)$ & $4.2(16)$ & $100(382)$ \\
\hline Total & $90.4(752)$ & $2.7(22)$ & $1.0(8)$ & $5.9(49)$ & $100(831)$ \\
\hline$p$ & $<.000$ & $<.000$ & $<.000$ & $<.000$ & $<.000$ \\
\hline
\end{tabular}

Chi-square tests were used to compare reported abuse in females and males (see Table 2). No significant gender differences were observed in the experience of physical abuse with or without sequelae/injury before age 13 only, after 13 only, or in the experience of abuse without sequelae/injury both before and after age 13 (see Table 2). There was, however, a trend for women to experience more physical abuse with sequelae/injury both before and after age 13 , than for men $(p=.06)$. Chi-square tests showed that reported abuse before and after 13 was significantly more frequent than that reported before 13 only, or after 13 only. This held for males and for females and for the sample as whole as well as for physical abuse with and without sequelae/injury (all $p$ values $<.001$, see Table 2 ).

\section{Perpetrator of physical abuse}

The type of physically abusive behavior was examined by gender of the perpetrator (Table 3 ). Chi-square test was used to test the possible association between the gender of the subject and the gender of the

Table 3

Experience of types of physical abuse without sequelae/injury before age 13 and gender of perpetrator

\begin{tabular}{lcc}
\hline Perpetrator & & \\
\hline Gender of respondent & Mother, $\%(N)$ & Father, $\%(N)$ \\
\hline A. "Whipping" category of abuse without sequelae/injury before age & $13(n=194)$ \\
Female $(N=106)$ & $75(79)$ & $25(27)$ \\
Male $(N=88)$ & $51(45)$ & $49(43)$ \\
Total $(N=194)$ & $64(124)$ & $36(70)$ \\
$p$ & $<.000$ & $<.000$ \\
B. "Slapping/ kicking" category of abuse without sequelae/injury before age $13(n=107)$ \\
Female $(N=59)$ & $63(37)$ & $37(22)$ \\
Male $(N=48)$ & $31(15)$ & $69(33)$ \\
Total $(N=107)$ & $49(52)$ & $51(55)$ \\
$p$ & $<.000$ & $<.000$
\end{tabular}


Table 4

Distribution of sexual abuse by age and gender

\begin{tabular}{llllll}
\hline $\begin{array}{l}\text { Gender of } \\
\text { respondent }\end{array}$ & $\begin{array}{l}\text { No sexual } \\
\text { abuse, } \%(N)\end{array}$ & $\begin{array}{l}\text { Before 13 only, } \\
\%(N)\end{array}$ & $\begin{array}{l}\text { After 13 only, } \\
\%(N)\end{array}$ & $\begin{array}{l}\text { Before and after13, } \\
\%(N)\end{array}$ & Total, \% $(N)$ \\
\hline Female & $97.3(435)$ & $1.1(5)$ & $0.7(3)$ & $0.9(4)$ & $100(447)$ \\
Male & $97.4(378)$ & $1.6(6)$ & $0.8(3)$ & $0.3(1)$ & $100(388)$ \\
Total & $97.3(813)$ & $1.3(11)$ & $0.7(6)$ & $0.6(5)$ & $100(835)$ \\
$p$ & $n s$ & $n s$ & $n s$ & $n s$ & $n s$ \\
\hline
\end{tabular}

perpetrator of the reported abuse for the two most widely reported types of abuse involving "whipping" and "slapping/kicking" but of the milder variety without physical sequelae/injury. Table 3 shows that most females who reported "whipping" experienced this from their mothers (75\%). This was significantly different from men $(p<.0001)$ who reported that their mothers perpetrated the "whipping" in $51 \%$ of the cases. Although "slapping/kicking" was perpetrated equally by mother or father in the series as a whole (see Table 3, bottom row), women experienced more from mothers than did men $(p<.05)$.

\section{Sexual abuse-age and gender}

Table 4 examines gender and age in rates of sexual abuse. There were low overall rates for both females $(2.7 \%)$ and males $(2.6 \%)$ and no differences found by age. However, low prevalence limits further analysis.

\section{Prevalence of abuse in three cultures}

Table 5 compares the prevalences of abuse in different age groups in three cultures utilizing the CHQ. When abuses at any age are examined it can be seen that the Portuguese series has significantly lower rates for each type of abuse (Table 5, rows 10-12). The same result is shown for all types of abuse before 13 (Table 5, rows 1-3), but only sexual abuse after age 13 (rows 4-6). Sexual abuse at any age was significantly lower in the Portuguese series than in the other series. Physical abuse with sequelae/injury was more likely to be similar in the three series when it continued into adolescence.

However, there are a few points of similarity between the Portuguese and Spanish series: physical abuse without sequelae/injury and that beginning before age 13 is similar at $29 \%$ in the Spanish series and $24.9 \%$ in the Portuguese (row 1, A vs. C, $n s$ ). Physical abuse with sequelae/injury before and after 13 is almost identical (row 8, A vs. C 5.3\% and 5.9\%, respectively). However, physical abuse with sequelae/injury at any age, although indicating closer rates in the two European settings (Spain 15.2\% and Portugal 9.5\% compared with the US 20.9\%), still found Portugal to have significantly lower rates (row 11). Thus, in comparing the series in the three different countries, rates in Portugal are consistently lower for most types of abuse.

\section{Care in childhood}

Two indicators of care in childhood were examined: care from an adult and predictable routine. The majority of the series reported having an adult who 'really cared about me' in childhood 'often' or 'very often' (87\% or $749 / 857)$. Women $(49.2 \%$ or $249 / 506)$ and men $(45.3 \%$ or $193 / 426)$ reported similar levels of having an adult who cared 'very often' $(n s)$. Predictability of childhood routine was reported 
Table 5

The prevalence of childhood abuse reported by the CHQ in three different cultures by age of onset

\begin{tabular}{|c|c|c|c|c|}
\hline \multirow[t]{2}{*}{ Type of abuse } & \multicolumn{3}{|l|}{ Country of study } & \multirow[t]{2}{*}{$p$} \\
\hline & Spain $^{\mathrm{a}}(n=403)$ & $\mathrm{US}^{\mathrm{b}}(n=374)$ & Portugal $(n=932)$ & \\
\hline \multicolumn{5}{|l|}{ Percent abuse before age 13} \\
\hline Physical without sequelae/injury & 29.0 & 35.6 & 24.9 & $<.001$ \\
\hline Physical with sequelae/injury & 7.4 & 9.7 & 2.7 & $<.0001$ \\
\hline Sexual & 5.1 & 4.0 & 1.3 & $<.001$ \\
\hline \multicolumn{5}{|l|}{ Percent abuse after age 13} \\
\hline Physical without sequelae/injury & 1.3 & 0.9 & 2.2 & $n s$ \\
\hline Physical with sequelae/injury & 2.5 & 2.6 & 1.0 & $n s$ \\
\hline Sexual & 3.3 & 4.1 & 0.7 & $<.001$ \\
\hline \multicolumn{5}{|c|}{ Percent abuse both before and after age 13} \\
\hline Physical without sequelae/injury & 63.5 & 55.1 & 45.0 & $<.0001$ \\
\hline Physical with sequelae/injury & 5.3 & 8.6 & 5.9 & $n s$ \\
\hline Sexual & 3.8 & 1.9 & 0.6 & .001 \\
\hline \multicolumn{5}{|c|}{ Percent abuse either before or after age 13} \\
\hline Physical without sequelae/injury & 93.8 & 91.7 & 72.1 & $<.0001$ \\
\hline Physical with sequelae/injury & 15.2 & 20.9 & 9.5 & $<.0001$ \\
\hline Sexual & 12.2 & 10.0 & 2.6 & $<.0001$ \\
\hline
\end{tabular}

a Spain (de Paúl et al., 1995).

${ }^{\text {b }}$ USA (Milner et al., 1990).

by only $58 \%(477 / 827)$ of the series with $11 \%(95 / 827)$ reporting 'never' having a predictable home life in childhood. Women $(22.3 \%$ or $102 / 457)$ were more likely to rate predictability 'very often' than men $(14.1 \%$ or $56 / 396 ; p=.006)$.

The absence of care and predictable routine in childhood were examined in association with abusive experience as an additional marker for childhood adversity and poor parenting. A relationship was confirmed only in the more serious abuses beginning in the teenage years. Thus, of those without a caring adult $13.7 \%$ (14/102) reported physical abuse with sequelae/injury after age 13 versus 5.3\% (38/712) of those with a caring adult $(p=.001)$. Similarly, those with no caring adult more often reported sexual abuse after age $13(5.8 \%$ or $6 / 103)$ than those with a caring adult $(.8 \%, 6 / 712 ; p=.000)$. Only one type of abuse was related to the lack of a predictable routine, physical abuse with sequelae/injury after age 13: $9.3 \%$ (30/322) with no predictable routine versus 4.7\% (22/467) with predictable routine, $p=.01$. Thus, self-report of lack of care in childhood relates to abuse as expected, but mainly in adolescence.

\section{Discussion}

This report describes the first use of a standardized, retrospective, self-report measure of childhood and adolescent abuse in a large sample in Portugal. It shows abuse at any level was very prevalent (73\%), but significantly lower than rates reported in the USA (92\%; Milner et al., 1990) and in neighboring Northern 
Spain (94\%; de Paúl et al., 1995). Consistent with the other studies, almost all physical abuse began before age 13, but over half continued into adolescence. No significant gender differences were found overall in the reporting of physical abuse, although men were more likely to report early physical abuse with sequelae/injury than women. However, the study reported here found some gender differentiation concerning the perpetrator of mild forms of physical abuse without sequelae/injury. Among women who experienced "whipping" and "slapping/kicking" this was more often perpetrated by their mothers than was the case for men. Rates of sexual abuse $(2.6 \%)$ were significantly lower than those found in the US $(10.1 \%)$ and in Spain (12.2\%). Low numbers precluded more detailed analysis, but the lack of a gender difference in being the victim of sexual abuse in the study reported here, is in direct contrast to the US and Spanish findings where women had higher rates.

A relationship between more severe abuses and the lack of a caring adult and unpredictable routine is consistent with other studies that show a high correlation between both physical and sexual abuse and parental neglect (Bifulco et al., 1994). Why this association holds only in teenage years in this series is unclear.

There are at least three limitations of this study. First, the participation rate in the study was $69 \%$. Although these are similar, or even higher, than those in similar community-based studies, the study may still have missed the more vulnerable individuals with higher rates of abuse who might be excluded from the school system or separated from their children (Eisen \& Carlson, 1998; Epps et al., 1999).

Second, the interpretation of these results are somewhat limited by the self-report nature of the measure. For instance, we cannot know whether the lower reporting of abuse reflects actual experience in Portugal or represents a greater unwillingness to disclose, a factor identified in explaining lower rates in other European countries (Finkelhor, 1994). However, little difference in reporting bias might be expected from that in neighboring Northern Spain, rates of which were substantially higher-for abuse overall and for sexual abuse- - but similar for severe physical abuse. The trend towards an increased reporting of serious physical abuse in Portuguese females indicates there is no bias in female under-reporting. Therefore, if any gender-based under-reporting in Portuguese women did occur, it may be specific to reporting of sexual matters. This issue will be examined in subsequent reports in relation to intensive interview assessments of abuse in a subseries.

Third, this is the first use of a US-designed standardized questionnaire in the Portuguese context. It is possible that some cultural elements in reporting of sensitive childhood material were not adequately reflected in the form of questioning. This will be explored in the second intensive part of the study when detailed face-to-face questioning about childhood experience and abuse will be undertaken.

Despite these limitations, the results of the study are important as the first steps in mapping the Portuguese experience of childhood and adolescent abuse. Various explanations of the findings need to be explored. One difference between this series and the US and Spanish ones concerns the age and life stage of the respondents. In the US and Spanish study the participants were all students, average age between 19 and 20. The current study utilizes a series of parents with children in elementary school, average age 37. One possible explanation for the lower rates of abuse in this sample may be due to the focus on parents: any association of childhood abuse with problems in the parenting role such as childlessness would preclude those individuals from the study (e.g., Kinzl et al., 1995). The other factor concerns the relative stability of the Portuguese families in this series. Nearly all were two-parent families, with low rates of remarriage or reconstituted families, consistent with lower abuse histories (Belt \& Abidin, 1996; Crouch et al., 1995). Similarly most of the parents were employed and in lower middle-class occupations. This would also be consistent with lower childhood adversity experience-one consequence of which is 
downward social drift (e.g., Kotch et al., 1995). One particular hypothesis that needs to be explored is whether lower reported sexual abuse for women may be related to higher female status as a consequence of women's greater participation in the labor force in Portugal than in other European countries or the US.

An alternative explanation for variation between the three countries concerns the lapse of time between each. Thus, the highest rates corresponding to the earliest study, that conducted in the USA in the late 1980s, and the lowest corresponding to the latest study, that reported here in Portugal conducted in the late 1990s, with the Spanish study midway between. This constituted more than a 10-year time lag over the three studies. While this reduction over time may indicate that rates are reducing with increased global awareness of abuse issues, this does not account for differences in the patterns of abuse by gender and age in the three series and cultures. Contemporaneous cross-cultural studies would be required to assess differences in rates more accurately.

The gender findings may well prove to be specific to the Portuguese context, showing no overall differences in levels of abuse but a specific gender relationship of physical abuse from mothers to daughters and fathers to sons. The implication of this for adult dysfunction, parenting of same-sex children and for generalization of effects into the marital relationship needs to be explored. The negative effects of abuse beginning early in childhood are well documented, with evidence of a trajectory whereby later abuse can ensue (e.g., Figueiredo et al., 2001). However, the moderating impact of support in childhood also needs examining (Litty et al., 1996; Lynksey \& Fergusson, 1997), and if validation for the lower rates of abuse in the Portuguese series is provided then the social and family-based factors associated with this need to be documented. Thus, elements of the Portuguese family experience may hold lessons for child rearing in other countries and contexts.

\section{Acknowledgments}

We would like to thank the schools and parents who participated in the study.

\section{References}

Belt, W., \& Abidin, R. (1996). The relation of childhood abuse and early parenting experiences to current marital quality in a non-clinical sample. Child Abuse \& Neglect, 20, 1019-1030.

Benedict, M., Paine, L., Paine, L., Brandt, D., \& Stallings, R. (1999). The association of childhood sexual abuse with depressive symptoms during pregnancy, and selected pregnancy outcomes. Child Abuse \& Neglect, 23, 659-670.

Bifulco, A., Brown, G. W., \& Harris, T. O. (1994). Childhood experience of care and abuse (CECA): A retrospective interview measure. Journal of Child Psychology and Psychiatry, 35, 1419-1435.

Brayden, R. M., Deitrich-MacLean, G., Deitrich, M. S., Sherrod, K. B., \& Altemeier, W. A. (1995). Evidence for specific effects of childhood sexual abuse on mental well being and physical self esteem. Child Abuse \& Neglect, 19, 12551262.

Browne, K. D., \& Hamilton, C. E. (1998). Physical violence between young adults and their parents: Associations with a history of child maltreatment. Journal of Family Violence, 13, 59-79.

Crouch, J. L., Milner, J. S., \& Caliso, J. A. (1995). Childhood physical abuse, perceived social support, and socio-emotional status in adult women. Violence and Victims, 10, 273-283.

de Paúl, J., Milner, J., \& Múgica, P. (1995). Childhood maltreatment, childhood social support, and child abuse potential in a Basque sample. Child Abuse \& Neglect, 19, 907-920. 
Dube, S. R., Anda, R. F., Felitti, V. J., Chapman, D. P., Williamson, D. F., \& Gilles, W. H. (2001). Childhood abuse, household dysfunction, and the risk of attempted suicide throughout the life span: Findings from the adverse childhood experiences study. Journal of the American Medical Association, 24, 3120-3126.

Egami, Y., Fond, D. E., Greenfield, S. F., \& Crum, R. M. (1996). Psychiatric profile and socio-demographic characteristics of adults who report physically abusing or neglecting children. American Journal of Psychiatry, 153, 921-928.

Eisen, H. L., \& Carlson, E. V. (1998). Individual differences in suggestibility. Examining the influence of dissociation, absorption and a history of childhood abuse. Applied Cognitive Psychology, 12, 547-561.

Epps, J., Carlin, A. S., \& Ward, N. G. (1999). Adult anger expression and childhood physical abuse history: The effects of event memory versus self-labeling. Journal of Mental Health and Aging, 5, 175-185.

Epstein, M., \& Bottoms, B. (1998). Memories of childhood sexual abuse: A survey of young adults. Child Abuse \& Neglect, 22, $1217-1238$.

European Commission. (2002). Eurostat, Statistical office of the European Commission. http://europa.eu.int/comm/eurostat/.

Figueiredo, B., Fernandes, E., Matos, R., \& Maia, A. (2001). Maus tratos na infância: Trajectórias desenvolvimentais e intervenção psicológica na idade adulta. In R. Abrunhosa \& C. Machado (Coords.), Violência e vítimas de crimes, vol. I: Adultos (pp. 200-263). Coimbra: Quarteto Editora.

Finkelhor, D. (1984). Child sexual abuse: New theory and research. New York: The Free Press.

Finkelhor, D. (1994). The international epidemiology of child sexual abuse. Child Abuse \& Neglect, 18, $409-417$.

Fish, V., \& Scott, C. (1999). Childhood abuse recollections in a non-clinical population: Forgetting and secrecy. Child Abuse \& Neglect, 23, 791-802.

Gelles, R. J., \& Loseke, D. R. (Eds.). (1993). Current controversies on family violence. Newbury Park, CA: Sage.

Grimstad, H., \& Schei, B. (1999). Pregnancy and delivery for women with a history of child sexual abuse. Child Abuse \& Neglect, $23,81-90$.

Instituto Nacional de Estatística. (1999). Anuário estatístico da região Norte. Lisboa: Instituto Nacional de Estatística.

Kessler, R. C., Davis, C. G., \& Kendler, K. S. (1997). Childhood adversity and adult psychiatry disorder in the US National Comorbidity Survey. Psychological Medicine, 27, 1101-1119.

Kinzl, J., Traweger, C., \& Biebl, W. (1995). Sexual dysfunctions: Relationship to childhood sexual abuse and early family experiences in a nonclinical sample. Child Abuse \& Neglect, 19, 785-792.

Kotch, J. B., Browne, D. C., Stewart, P. W., Ruina, E., Holt, K., Lowman, B., \& Jung, J. W. (1995). Risk of child abuse or neglect in a cohort of low income children. Child Abuse \& Neglect, 19, 1115-1130.

Liem, J., \& Boudewyn, A. (1999). Contextualizing the effects of childhood sexual abuse on adult self and social functioning: An attachment theory perspective. Child Abuse \& Neglect, 23, 1141-1157.

Litty, C. G., Kowalski, R., \& Minor, S. (1996). Moderating effects of physical abuse and perceived social support on the potential to abuse. Child Abuse \& Neglect, 20, 305-314.

Lynksey, M. T., \& Fergusson, D. M. (1997). Factors protecting against the development of adjustment difficulties in young adults exposed to childhood sexual abuse. Child Abuse \& Neglect, 21, 1177-1190.

MacMillan, H. L., Fleming, J. E., Streiner, D. L., Lin, E., Boyle, M. H., Jamieson, E., Duku, E., Walsh, C. A., Wong, M. Y. Y., \& Beardslee, W. (2001). Childhood abuse and lifetime psychopathology in a community sample. American Journal of Psychiatry, 158, 1878-1883.

Matos, R., Figueiredo, B., Maia, A., Fernandes, E., \& Ribeiro, L. (1999). Versão portuguesa do "Childhood History Questionnaire” (CHQ). Braga: Departamento de Psicologia, Universidade do Minho.

McGuigan, W. M., \& Pratt, C. C. (2001). The predictive impact of domestic violence on three types of child maltreatment. Child Abuse \& Neglect, 25, 869-883.

Melchert, T. (2000). Clarifying the effects of parental substance abuse, child sexual abuse, and parental caregiving on adult adjustment. Professional Psychology, 31, 64-69.

Milner, J. S., Robertson, K. R., \& Rogers, D. L. (1990). Childhood history of abuse and adult child abuse potential. Journal of Family Violence, 5, 15-34.

Mollerstrom, W. W., Patchner, M. A., \& Milner, J. S. (1995). Child maltreatment: The United States air force's response. Child Abuse \& Neglect, 19, 325-334.

Mullen, P. E., Martin, J. L., Anderson, J. C., Romans, S. E., \& Herbison, G. P. (1993). Childhood sexual abuse and mental health in adult life. British Journal of Psychiatry, 163, 721-732.

Nobes, G., Smith, M., Upton, P., \& Heverin, A. (1999). Physical punishment by mothers and fathers in British homes. Journal of Interpersonal Violence, 14, 887-902. 
Peters, D. K., \& Range, L. M. (1995). Childhood sexual abuse and current suicidality in college women and men. Child Abuse \& Neglect, 19, 335-341.

Polusny, M. A., \& Foulette, V. M. (1995). Long-term correlates of child sexual abuse: Theory and review of the empirical literature. Applied \& Preventive Psychology, 4, 143-166.

Rosen, L. N., \& Martin, L. (1996). Impact of childhood abuse history on psychological symptoms among male and female soldiers in the US army. Child Abuse \& Neglect, 20, 1149-1160.

Shapiro, D., \& Levendosky, A. (1999). Adolescent survivors of childhood sexual abuse: The mediating role of attachment style and coping in psychological and interpersonal functioning. Child Abuse \& Neglect, 23, 1175-1191.

US Department of Health and Human Services. (1986). National Center on Child Abuse and Neglect. Washington, DC: US Government Printing Office.

US Department of Health and Human Services. (1988). National Study of the Incidence and Severity of Child Abuse and Neglect. Washington, DC: US Government Printing Office.

US Department of Health and Human Services. (1996). The Third National Incidence Study of Child Abuse and Neglect. Washington, DC: US Government Printing Office.

\section{Résumé}

Objectif: Cette étude porte sur la prévalence des mauvais traitements physiques et sexuels tels que dévoilés par des parents portugais faisant partie d'un échantillon considérable.

Méthode: Près de mille parents (506 mères et 426 pères) ont été choisis par le biais du système scolaire élémentaire de la région Nord du Portugal. Tous ont complété la version portugaise du questionnaire Childhood History [Journal of Family Violence 5 (1990) 15].

Résultats: Les résultats démontrent une prévalence de $73 \%$, cependant pour les mauvais traitements physiques les plus graves (avec séquelles ou des blessures), la prévalence est de $9.5 \%$. La plupart des mauvais traitements physiques ont eu lieu avant l'âge de 13 ans, et la moitié se sont prolongés après cet âge. On n'a remarqué aucune différence entre les sexes. Toutefois, pour ce qui est des mauvais traitements moins graves (sans séquelles ou blessures), on note que les femmes fouettées ou giflées ou victimes de coups de pieds sont plus aptes à avoir été frappées par leur mère plutôt que par leur père. Parmi les hommes giflés ou victimes de coups de pieds, le père en était habituellement l'auteur. On a noté une prévalence de $2.6 \%$ pour les mauvais traitements sexuels, sans différence entre les hommes et les femmes. Pour les cas sévères on remarque que les victimes ont reçu peu d'appui de la part d'un adulte aidant, ceci durant l'adolescence seulement. Le questionnaire a décelé une prévalence de mauvais traitements moins élevée au Portugal qu'aux États Unis ou en Espagne.

Conclusions: Cette étude est la première étude rétrospective en son genre, utilisant un échantillon considérable de parents portugais. Malgré un taux de participation de $69 \%$, les résultats dénotent moins de maltraitance que dans les échantillons américains ou espagnols.

\section{Resumen}

Objetivo: El estudio examina la prevalencia auto-reportada del abuso físico y sexual en la niñez en una amplia muestra de padres portugueses.

Método: Cerca de 1,000 padres (506 madres y 426 padres) fueron seleccionados a través de las escuelas públicas primarias del área norte de Portugal. Todos completaron la versión portuguesa del Cuestionario sobre la Historia de la Niñez (CHQ) [Journal of Family Violence 5 (1990) 15]. 
Resultados: Los resultados demuestran que la prevalencia del abuso fue un 73\%, pero el $9.5 \%$ reportó abuso físico más severo incluyendo secuelas y heridas. La mayor parte del abuso físico comenzó antes de los 13 años, y la mitad continuó hasta después de la edad de 13 años. Sin embargo, entre el abuso físico leve sin secuela ni heridas, aquellas mujeres que recibieron "latigazos," o "bofetadas/puntapiés" tenían mayor tendencia a recibirlas de sus madres que de sus padres. Entre los hombres que fueron "abofeteados y pateados" el abuso tenía más probabilidad de venir de sus padres. Se encontraron tasas bajas de abuso sexual en $2.6 \%$ sin diferencias de género ni edad. La falta de un adulto de apoyo en la niñez se relacionaba con los abusos más severos, pero solo en la adolescencia. Las tasas de abuso portuguesas estaban consistentemente más bajas que las reportadas en los Estados Unidos y en estudios españoles utilizando el CHQ.

Conclusiones: Este es el primer estudio retrospectivo con auto-reporte sobre el abuso en la niñez en una amplia muestra de padres portugueses, y aun con una participación del 69\%, muestra tasas más bajas que en las muestras en EUA y en España. 